\title{
Ammonia Transport by Early and Late Proximal Convoluted Tubule of the Rat
}

David W. Good and Thomas D. DuBose, Jr.

Renal-Electrolyte Physiology Laboratory, Departments of Internal Medicine, Physiology and Biophysics,

University of Texas Medical Branch, Galveston, Texas 77550

\begin{abstract}
Free-flow micropuncture experiments were performed to examine ammonia transport separately in early and late proximal convoluted tubule (PCT) of the rat. In control rats, ammonia was secreted along the early PCT but was reabsorbed along the late PCT. In rats with chronic metabolic acidosis, ammonia secretion along the early PCT was increased compared with controls, and ammonia absorption by the late PCT was converted to small net ammonia secretion. In the acidotic rats, ammonia secretion rate in the early PCT was six times higher than that in the late PCT. Thus, most or all of ammonia secretion by the PCT occurred along its early portion. In control and acidotic rats, luminal $\mathrm{NH}_{3}$ concentration in the early PCT was significantly higher than that in the late PCT, indicating that ammonia is not in diffusion equilibrium throughout the renal cortex. It is proposed that differences in ammonia transport rate in early vs. late PCT may be due to differences in ammonia production rate and/or to differences in the rate of an ammonia backflux that detracts from net ammonia secretion.
\end{abstract}

\section{Introduction}

The regulation of plasma bicarbonate concentration and systemic arterial $\mathrm{pH}$ depends critically on the ability of the kidneys to produce and excrete ammonia ${ }^{1}(1,2)$. The proximal tubule has been identified as the principal site of renal ammonia production as well as an important site of ammonia secretion. Direct measurements of ammonia production by defined segments of the rat nephron have shown that all segments of the proximal tubule produce ammonia from glutamine and that the bulk of renal ammonia production occurs in the proximal tubules (3). In addition, results of micropuncture studies have shown that the amount of ammonia delivered to the end of the superficial prox-

Results of these experiments were presented, in part, at the 1986 Annual Meeting of the American Federation for Clinical Research (1986. Clin. Res. 34:697A) and at the 70th Annual Meeting of the Federation of American Societies for Experimental Biology (1986. Fed. Proc. 45:508).

Address correspondence and reprint requests to Dr. Good, RenalElectrolyte Physiology Laboratory, Department of Internal Medicine, John Sealy Hospital, Rm. 4.200, Rt. E-62, University of Texas Medical Branch, Galveston, TX 77550.

Received for publication 19 September 1986.

1. In this paper, the terms ammonia and total ammonia indicate the sum of $\mathrm{NH}_{3}$ and $\mathrm{NH}_{4}^{+} . \mathrm{NH}_{3}$ indicates free-base ammonia; $\mathrm{NH}_{4}^{+}$indicates ammonium ion.

J. Clin. Invest.

(C) The American Society for Clinical Investigation, Inc. $0021-9738 / 87 / 03 / 0684 / 08 \$ 1.00$

Volume 79, March 1987, 684-691 imal convoluted tubule (PCT) ${ }^{2}$ exceeds the amount of ammonia that is filtered and can account for up to $100 \%$ of the ammonia excreted in the final urine (4-7). Because of such observations, it has generally been assumed that ammonia secretion occurs uniformly along the length of the proximal tubule. Little or no direct information is available, however, regarding rates of ammonia transport by different portions of the proximal tubule in vivo. The purpose of the present experiments, therefore, was to evaluate ammonia transport separately in the early and late PCT of the rat. Our aims were to compare ammonia transport rates in the early and late PCT of normal rats and to examine the effect of chronic metabolic acidosis on ammonia transport by early and late PCT segments.

\section{Methods}

Male mutant Munich-Wistar rats (100-240 g) received commercial rat chow (Ralston Purina Co., St. Louis, MO) and drank tap water (controls) or $0.28 \mathrm{M} \mathrm{NH}_{4} \mathrm{Cl}$ (chronic metabolic acidosis) for 4-15 d before experiments. The rats were anesthetized by intraperitoneal injection of 100 $\mathrm{mg} / \mathrm{kg}$ body wt Inactin (Byk-Gulden, Konstanz, Federal Republic of Germany) and placed on a thermostatically controlled $\left(37^{\circ} \mathrm{C}\right)$ table. A tracheostomy was performed and the left jugular vein was cannulated for infusion of physiological saline and administration of supplementary anesthesia, if necessary. The left femoral artery was cannulated to monitor blood pressure and for collection of arterial blood samples. The left kidney was exposed by a flank incision and prepared for micropuncture of the renal cortex as previously described (8-10).

To replace surgical fluid losses, control rats received saline-bicarbonate ( $120 \mathrm{mM} \mathrm{NaCl}, 25 \mathrm{mM} \mathrm{NaHCO}$, and $4 \mathrm{mM} \mathrm{KCl}$ ) equal to $1 \%$ body wt in $15 \mathrm{~min}$. This solution was then infused at $1 \%$ body $\mathrm{wt} / \mathrm{h}$ for the remainder of the experiment. Acidotic rats were infused identically with $140 \mathrm{mM} \mathrm{NaCl}$ and $4 \mathrm{mM} \mathrm{KCl}$. In all experiments in which ammonia transport rates were measured and in some experiments in which $\mathrm{NH}_{3}$ concentrations were determined, [methoxy- ${ }^{3} \mathrm{H}$ ]inulin was added to the infusion solution and administered at a rate of $190 \mu \mathrm{Ci} / \mathrm{h}$. Arterial blood acid-base status was carefully monitored and maintained as previously described (10). Urine from both kidneys was collected via a bladder catheter for determination of glomerular filtration rate and ammonia excretion rates.

Clearance periods and proximal tubule micropuncture were begun $\sim 1 \mathrm{~h}$ after the start of the inulin infusion. Proximal tubules possessing several surface convolutions were identified by injecting dyed $\mathrm{NaCl}$ solution into random proximal segments. Two series of experiments were performed. In the first series, total ammonia transport rates were determined separately for the early and late PCT. This was accomplished by collecting paired samples of tubule fluid from an early and late segment of the same PCT. Tubule fluid samples were collected for timed intervals (2.5-6 min) using sharpened 8-10- $\mu \mathrm{m}$ OD glass pipettes as previously described $(8,9)$. In each tubule, the late proximal segment was punctured before the early proximal segment to prevent leakage of tubule fluid. In a second series of experiments, luminal $\mathrm{NH}_{3}$ concentrations were determined by making paired measurements of total ammonia concentration

2. Abbreviations used in this paper: PCT, proximal convoluted tubule; $\mathrm{TF} / \mathrm{P}$, tubule fluid to arterial plasma concentration ratio. 
and in situ pH at early and late PCT sites. At the end of experiments in both series, tubules were injected with latex for determination of tubule length between early and late proximal puncture sites.

Analysis. Blood acid-base values and urine $\mathrm{pH}$ were measured using a blood-gas analyzer (Corning Medical, Corning Glass Works, Medfield, MA). Urine volumes were determined by weighing. Tubule fluid sample volumes were measured in a calibrated constant-bore tube. Radioactivity of inulin in tubule fluid, arterial plasma and urine was measured by liquid scintillation counting (Packard Instrument Co. Inc., United Technologies, Downers Grove, IL) using Aquasol (New England Nuclear, Boston, MA).

Total ammonia concentrations in tubule fluid, arterial plasma, and urine were measured by microfluorometry using the glutamate dehydrogenase reaction as previously described $(11,12)$. The method is highly specific and permits experimental samples to be measured immediately after collection with no prior processing. Ammonia added to plasma or urine is recovered completely $(11,12)$. For the sample volume used in these experiments $(10 \mathrm{nl})$, the method is able to resolve differences of $\sim 0.05 \mathrm{mM}$ between samples for the range $0.5-1.0 \mathrm{mM}$. To test for nonspecific fluorescence that may result from components of fluid samples unrelated to the glutamate dehydrogenase reaction, early and late proximal tubule fluid samples were injected into the fluorometer under conditions in which the assay reagent contained no glutamate dehydrogenase (12). The change in fluorescence obtained under these conditions always measured $<0.05 \mathrm{mM}$ total ammonia, indicating that no significant background signal was present. As demonstrated previously (12), there is no detectable loss of ammonia from micropuncture samples into the oil in collection pipettes during sample handling under the conditions of our experiments.

In situ pH in early and late PCT segments was measured using singlebarreled glass-membrane microelectrodes as previously described (13). In experiments in which luminal $\mathrm{NH}_{3}$ concentrations were determined, $\mathrm{pH}$ and total ammonia concentration always were measured in the same PCT segment. Because pH electrodes tend to make a larger hole in tubule segments than collection pipettes, $\mathrm{pH}$ values always were measured after tubule fluid samples were collected. To be certain that the $\mathrm{pH}$ measurements were not influenced by this procedure, $\mathrm{pH}$ was measured in acidotic rats in early and late PCT segments that had not previously been punctured with a collection pipette. Mean $\mathrm{pH}$ measured at early $(7.04 \pm 0.04$, $n=19)$ and late $(6.57 \pm 0.02, n=19)$ proximal sites in these tubules did not differ from values measured in tubules that had previously been punctured with fluid collection pipettes (Table III).

Calculations. Rates of total ammonia filtration for individual nephrons were calculated as $[\mathrm{Am}]_{\mathrm{p}} \times$ sngfr, where $[\mathrm{Am}]_{\mathrm{p}}$ is arterial plasma total ammonia concentration (in millimoles per liter) and sngfr is single nephron glomerular filtration rate (in nanoliters per minute), calculated as the product of early proximal tubule flow rate and tubule fluid to plasma inulin concentration ratio $\left(\mathrm{TF} / \mathrm{P}_{\mathbf{I n}}\right)$. Rates of total ammonia de- livery to early and late proximal puncture sites were calculated as the products of total ammonia concentrations and flow rates. For example, the rate at which total ammonia was delivered to the late proximal tubule site, $A \dot{m}_{\mathrm{LP}}$, was $A \dot{m}_{\mathrm{LP}}=V_{\mathrm{LP}} \cdot[A m]_{\mathrm{LP}}$, where $[A m]_{\mathrm{LP}}$ is the total ammonia concentration in late proximal fluid and $V_{\mathrm{LP}}$ is the fluid collection rate. The absolute rate of total ammonia transport for the early PCT was calculated as the difference between total ammonia filtration rate and the rate of total ammonia delivery to the early proximal puncture site. Total ammonia transport rate for the late PCT was calculated as the difference between ammonia delivery rates to early and late proximal puncture sites. Positive transport rates indicate net total ammonia absorption; negative rates indicate net total ammonia secretion.

Concentrations of $\mathrm{NH}_{3}\left(\left[\mathrm{NH}_{3}\right]\right)$ in early and late PCT were calculated from measured total ammonia concentrations $([\mathrm{Am}])$ and in situ $\mathrm{pH}$ values at $37^{\circ} \mathrm{C}$ as $\left[\mathrm{NH}_{3}\right]=[\mathrm{Am}] / 1-10^{\mathrm{pK}-\mathrm{pH}}$, where $\mathrm{pK}_{\mathrm{a}}^{\prime}$, the acidic dissociation constant for ammonium, was 9.026. $\mathrm{pK}_{\mathrm{a}}^{\prime}$ was calculated as described previously (12) using a thermodynamic dissociation constant for ammonium of 8.890 at $37^{\circ} \mathrm{C}$ (zero ionic strength) and an ionic strength of $0.144 \mathrm{eq} /$ /iter for proximal tubule fluid. $\mathrm{NH}_{3}$ concentrations always were determined in an early and late segment of the same proximal tubule.

Mean values are presented \pm SE. Differences between means were evaluated using the $t$ test for paired or unpaired data as appropriate. $P$ values of $<0.05$ were regarded as indicating statistical significance.

\section{Results}

Table I shows blood acid-base values and whole kidney data for all rats. Glomerular filtration rate did not differ in control and acidotic rats. Arterial blood $\mathrm{pH}$, arterial blood bicarbonate concentration, and urine $\mathrm{pH}$ were reduced in the acidotic rats. Urine total ammonia concentration, total ammonia excretion rate, and plasma total ammonia concentration were increased in the acidotic rats. Mean body weight at the time of experiments did not differ in the two groups (control, $169 \pm 5 \mathrm{~g}$; acidosis $180 \pm 12 \mathrm{~g})$.

Total ammonia transport rates in early and late PCT. Total ammonia transport rates were measured in 10 control and 10 acidotic rats. Table II (mean values) and Fig. 1 (individual data) summarize micropuncture values obtained at early and late proximal tubule sites. Total ammonia concentration in tubule fluid did not differ significantly in the early and late proximal tubule in control rats (Fig. 1, Table II). In contrast, total ammonia concentration increased significantly between early and late proximal sites in rats with chronic metabolic acidosis (Fig. 1,

Table I. Blood Acid-Base Values and Whole Kidney Data for Control and Acidotic Rats

\begin{tabular}{|c|c|c|c|c|c|c|c|c|}
\hline & \multicolumn{3}{|l|}{ Blood } & \multirow[b]{2}{*}{$\begin{array}{l}\text { Plasma } \\
{[A m]}\end{array}$} & \multirow[b]{2}{*}{ GFR } & \multicolumn{3}{|l|}{ Urine } \\
\hline & $\mathrm{pH}$ & {$\left[\mathrm{HCO}_{3}\right]$} & $\mathrm{PCO}_{2}$ & & & pH & {$[\mathrm{Am}]$} & $U_{A m} V$ \\
\hline & $U$ & $m M$ & $m m H g$ & $m M$ & $\mathrm{ml} / \mathrm{min} \cdot \mathrm{kidney}$ & $U$ & $m M$ & $\mu \mathrm{mol} / \mathrm{min} \cdot \mathrm{kidney}$ \\
\hline Control & 7.35 & 21.6 & 41.0 & 0.08 & 0.72 & 5.90 & 117 & 0.18 \\
\hline$(n=15)$ & \pm 0.01 & \pm 0.6 & \pm 1.6 & \pm 0.01 & \pm 0.07 & \pm 0.08 & \pm 10 & \pm 0.02 \\
\hline Acidosis & 7.23 & 17.9 & 44.0 & 0.11 & 0.75 & 5.62 & 273 & 0.97 \\
\hline$(n=15)$ & \pm 0.02 & \pm 0.8 & \pm 1.2 & \pm 0.01 & \pm 0.07 & \pm 0.05 & \pm 22 & \pm 0.09 \\
\hline$P$ & $<0.001$ & $<0.001$ & NS & $<0.05$ & NS & $<0.01$ & $<0.001$ & $<0.001$ \\
\hline
\end{tabular}

Values are means \pm SE. Numbers in parentheses are numbers of rats. GFR was determined in 13 control rats. $P$ values compare control vs. acidosis (unpaired $t$ test). [Am], total ammonia concentration. GFR, glomerular filtration rate. $U_{A m} V$, absolute total ammonia excretion rate. 
Table II. Proximal Tubule Micropuncture Data

\begin{tabular}{|c|c|c|c|c|c|}
\hline & {$[\mathrm{Am}]$} & $\mathrm{TF} / \mathrm{P}_{\mathrm{In}}$ & Flow rate & SNGFR & $\dot{A m}$ \\
\hline & $m M$ & & $\mathrm{nl} / \mathrm{min}$ & $\mathrm{nl} / \mathrm{min}$ & $\mathrm{pmol} / \mathrm{mir}$ \\
\hline \multicolumn{6}{|l|}{ Control } \\
\hline Early & 0.40 & 1.6 & 21.5 & 33.3 & 8.1 \\
\hline (30 tubules) & \pm 0.02 & \pm 0.1 & \pm 1.3 & \pm 1.6 & \pm 0.5 \\
\hline Late & 0.45 & 2.4 & 13.6 & 31.6 & 5.7 \\
\hline (27 tubules) & \pm 0.03 & \pm 0.1 & \pm 0.8 & \pm 1.5 & \pm 0.3 \\
\hline$P$ & NS & $<0.001$ & $<0.001$ & NS & $<0.001$ \\
\hline \multicolumn{6}{|l|}{ Acidosis } \\
\hline Early & $0.8^{*}$ & 1.7 & 21.0 & 33.9 & $16.0^{*}$ \\
\hline (25 tubules) & \pm 0.04 & \pm 0.1 & \pm 1.4 & \pm 1.9 & \pm 1.1 \\
\hline Late & $1.3^{*}$ & 2.3 & 15.1 & 32.8 & $18.1^{*}$ \\
\hline (25 tubules) & \pm 0.05 & \pm 0.1 & \pm 1.1 & \pm 1.8 & \pm 1.1 \\
\hline$P$ & $<0.001$ & $<0.001$ & $<0.001$ & NS & $<0.00$ \\
\hline
\end{tabular}

Values are means $\pm \mathrm{SE}$. Total ammonia filtration rate was $2.6 \pm 0.3$ $\mathrm{pmol} / \mathrm{min}$ in controls and $3.2 \pm 0.3 \mathrm{pmol} / \mathrm{min}$ in acidosis. $P$ values compare early vs. late proximal tubule (paired $t$ test). Tubule length between early and late proximal sites averaged $2.5 \pm 0.1 \mathrm{~mm}$. [Am], total ammonia concentration; $T F / P_{\mathrm{In}}$, tubule fluid to plasma inulin concentration ratio; SNGFR, single nephron glomerular filtration rate; Am, absolute total ammonia delivery rate.

* Value in acidosis significantly different from control (unpaired $t$ test).

Table II). The total ammonia concentration in both early and late proximal tubule fluid was higher in the acidotic rats than in controls (Table II). In both groups of rats, the TF/P inulin ratio increased and the tubule fluid flow rate decreased between early and late proximal tubule sites (Table II). Net fluid absorption rate between early and late proximal sites averaged 6-8 $\mathrm{nl} /$ $\mathrm{min}$. TF/P inulin ratios, tubule fluid flow rates, and single nephron glomerular filtration rate did not differ in control and acidotic rats (Table II). The tubule length measured between early and late proximal puncture sites averaged $2.5 \pm 0.1 \mathrm{~mm}$ (range 1.5 to $3.7 \mathrm{~mm}$ ) and did not differ in the two groups of rats. The total length of the accessible PCT in Munich-Wistar rats averages $4.8 \mathrm{~mm}(14,15)$. Thus, tubule length between glomerulus and early proximal puncture site was, on average, $2.3 \mathrm{~mm}$.
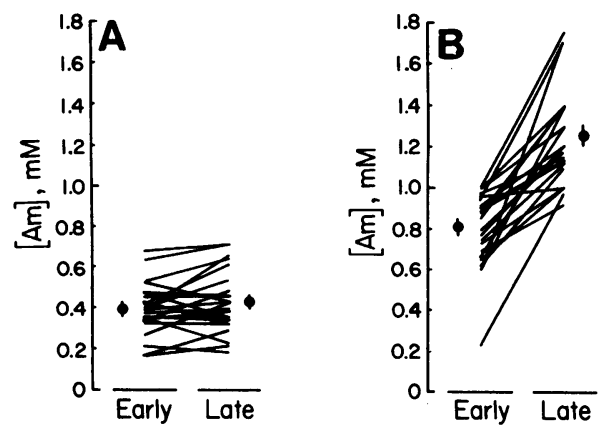

Figure 1. Tubule fluid total ammonia concentration $([\mathrm{Am}])$ measured in early and late segments of proximal tubule. Closed circles, means $\pm \mathrm{SE}$. Lines connect paired measurements made in the same tubule. $(A)$ Control, $(B)$ acidosis. $P$ values for early vs. late (paired $t$ test): control, NS; acidosis, $P<0.001$.

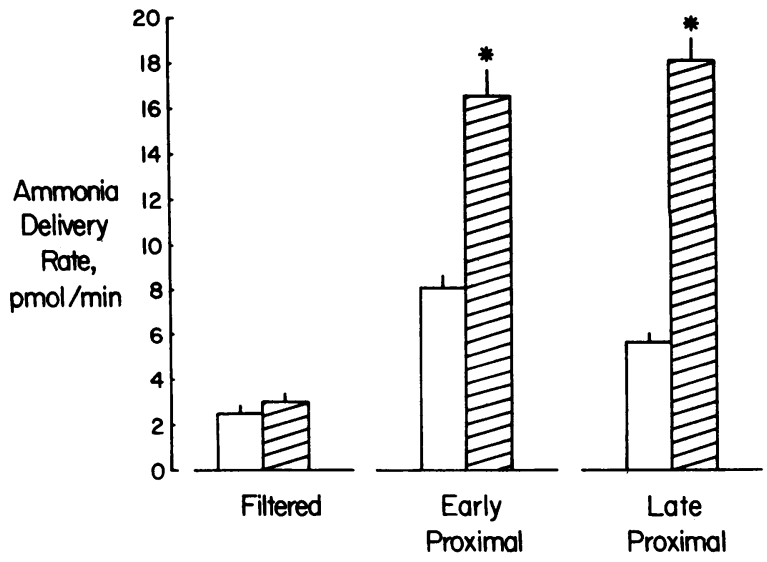

Figure 2. Total ammonia filtration rates and rates of total ammonia delivery to early and late proximal tubule sites. Bars are mean values \pm SE. Asterisks indicate delivery rate in acidosis different from control. Numbers of tubules same as in Table II. Open bars, control; hatched bars, acidosis.

Fig. 2 and Table II show absolute rates of total ammonia filtration and rates of total ammonia delivery to early and late proximal tubule sites. In both control and acidotic rats, delivery to the early proximal site exceeded the rate at which ammonia was filtered, indicating net ammonia secretion along the early PCT. In both groups of rats, however, delivery to the late proximal site differed relatively little from delivery to the early proximal site (Fig. 2, Table II). In control rats, late proximal delivery was slightly but significantly less than early proximal delivery, indicating small net ammonia absorption. In acidotic rats, ammonia delivery to the late proximal site was slightly greater than delivery to the early proximal site, but the rate of ammonia secretion was small compared with the rate observed along the early PCT. These results indicate that most or all of ammonia secretion by the PCT occurs along its early portion. This is illustrated directly by the absolute total ammonia transport rates summarized in Fig. 3. In control and acidotic rats, there was net secretion of total ammonia along the early PCT. The rate

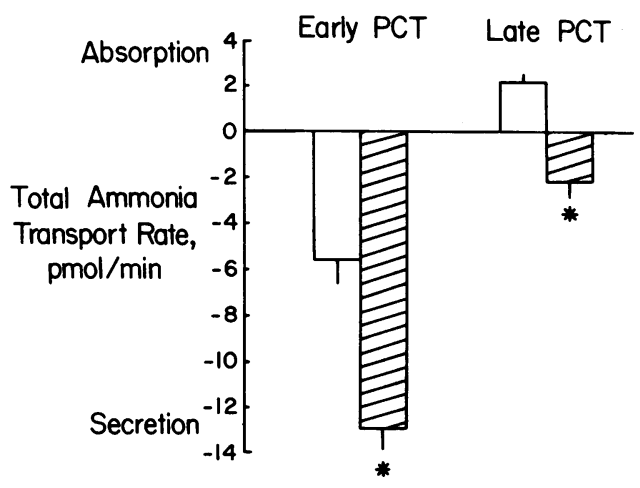

Figure 3. Total ammonia transport rate in early and late PCT. Bars are means \pm SE. Transport rates calculated as described in Methods. Numbers of tubules same as in Table II. Mean tubule length was 2.5 $\mathrm{mm}$ for late PCT and $2.3 \mathrm{~mm}$ for early PCT (see Results). All transport rates differ significantly from zero. Asterisks indicate net transport rate in acidosis significantly different from control $(P<0.001$, unpaired $t$ test). Late PCT transport rate differs significantly from early PCT transport rate in both groups of rats $(P<0.001$, paired $t$ test $)$. Open bars, control; hatched bars, acidosis. 
of early proximal secretion was greater in the acidotic rats $(-12.8 \pm 1.1 \mathrm{pmol} / \mathrm{min})$ than in controls $(-5.6 \pm 0.9 \mathrm{pmol} / \mathrm{min})$ (Fig. 3). In the late PCT, net total ammonia absorption in controls $(2.3 \pm 0.3 \mathrm{pmol} / \mathrm{min})$ was converted to net total ammonia secretion ( $-2.1 \pm 0.8 \mathrm{pmol} / \mathrm{min}$ ) during acidosis (Fig. 3). In the acidotic rats, the rate of ammonia secretion along the late PCT was considerably less than secretion along the early PCT (Fig. 3).

$\mathrm{NH}_{3}$ concentrations in early and late $\mathrm{PCT} . \mathrm{NH}_{3}$ concentrations were determined in PCTs in five control and five acidotic rats. The results are shown in Table III (mean values) and Fig. 4 (individual data). Total ammonia concentrations in tubule fluid (Table III) were similar to values obtained in the ammonia transport studies (Table II). pH in the late PCT was less than that in the early PCT in both groups of rats (Table III). In control and acidotic rats, $\mathrm{NH}_{3}$ concentration in the early PCT was significantly greater than that in the late PCT (Fig. 4). $\mathrm{NH}_{3}$ concentration in the early and late PCT was greater in acidotic rats than in controls (Table III). $\mathrm{NH}_{3}$ concentration determined in arterial blood averaged 1.6 $\pm 0.1 \mu \mathrm{M}$ and did not differ in control and acidotic rats (Table III). This value is considerably less than the mean $\mathrm{NH}_{3}$ concentrations of 7.0 and $9.6 \mu \mathrm{M}$ determined in the early PCT (Table III).

In experiments in which $\mathrm{NH}_{3}$ concentrations were determined, mean tubule length between early and late proximal sites averaged $2.2 \pm 0.2 \mathrm{~mm}$ and did not differ in control and acidotic rats. $\mathrm{TF} / \mathrm{P}$ inulin ratios for early $(1.7 \pm 0.1)$ and late $(2.3 \pm 0.1)$ proximal sites and single nephron glomerular filtration rate $(31.9 \pm 1.9 \mathrm{nl} / \mathrm{min})$ were determined in the 10 tubules studied in acidotic rats. These values were similar to values obtained in the ammonia transport studies (Table II).

Table III. $\mathrm{NH}_{3}$ Concentrations in Early and Late Proximal Convoluted Tubule and Arterial Blood

\begin{tabular}{|c|c|c|c|c|}
\hline & {$[\mathrm{Am}]$} & $\mathrm{pH}$ & {$\left[\mathrm{NH}_{3}\right]$} & $\begin{array}{l}\text { Arteria } \\
\text { blood } \\
{\left[\mathrm{NH}_{3}\right]}\end{array}$ \\
\hline & $m M$ & $U$ & $\mu M$ & $\mu M$ \\
\hline \multicolumn{5}{|c|}{ Control (9 tubules) } \\
\hline \multirow[t]{3}{*}{ Early } & 0.48 & 7.17 & 7.0 & \\
\hline & \pm 0.03 & \pm 0.06 & \pm 0.9 & \\
\hline & & & & $\begin{array}{r}1.5 \\
\pm 0.2\end{array}$ \\
\hline \multirow[t]{2}{*}{ Late } & 0.54 & 6.78 & 3.1 & \\
\hline & \pm 0.03 & \pm 0.04 & \pm 0.3 & \\
\hline$P$ & NS & $<0.001$ & $<0.005$ & \\
\hline \multicolumn{5}{|c|}{ Acidosis (10 tubules) } \\
\hline \multirow[t]{3}{*}{ Early } & $0.73^{*}$ & 7.16 & $9.6^{*}$ & \\
\hline & \pm 0.07 & \pm 0.04 & \pm 0.6 & \\
\hline & & & & $\begin{array}{r}1.6 \\
\pm 0.1\end{array}$ \\
\hline \multirow[t]{2}{*}{ Late } & $1.2^{*}$ & $6.60^{*}$ & $4.8^{*}$ & \\
\hline & \pm 0.1 & \pm 0.07 & \pm 0.6 & \\
\hline$P$ & $<0.001$ & $<0.001$ & $<0.001$ & \\
\hline
\end{tabular}

Values are means $\pm \mathrm{SE}$. $\mathrm{NH}_{3}$ concentrations calculated as described in Methods. $P$ values compare early vs. late PCT (paired $t$ test). Mean tubule length between early and late proximal sites was $2.2 \pm 0.2 \mathrm{~mm}$. * Value in acidosis different from control (unpaired $t$ test).
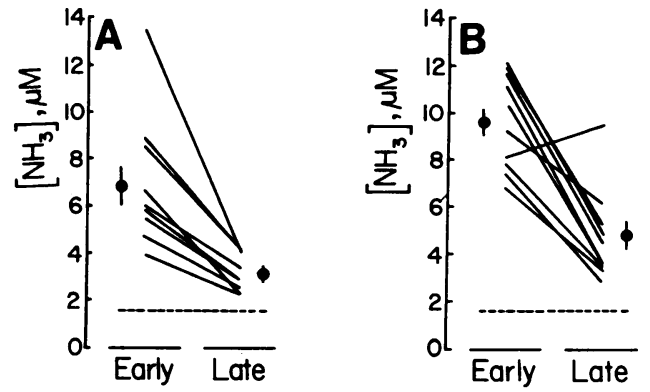

Figure 4. $\mathrm{NH}_{3}$ concentrations in early and late PCT. Closed circles, means \pm SE. Solid lines, connect paired values determined in the same tubule. Broken lines, $\mathrm{NH}_{3}$ concentration in arterial plasma $(1.6 \mu \mathrm{M})$. $(A)$ Control, $(B)$ acidosis. $P$ values for early vs. late (paired $t$ test): control, $P<0.001$; acidosis, $P<0.001$.

\section{Discussion}

Ammonium excreted in the urine is derived in large part from ammonium produced and secreted by cells of the proximal tubules $(1,16)$. The present study was designed to examine total ammonia transport separately in the early and late PCT to determine whether the ammonia transport rate varied as a function of proximal tubule length. The results demonstrate that the rate of total ammonia transport differs considerably in early and late PCT segments in the rat in vivo. In control rats, ammonia secretion occurs along the early PCT, but net ammonia absorption occurs along the late PCT (Fig. 3). In rats with chronic metabolic acidosis, ammonia secretion along the early PCT is increased compared with controls and ammonia absorption by the late PCT is converted to net ammonia secretion (Fig. 3). In acidotic rats, the total ammonia secretion rate along the early PCT was approximately six times that observed along the late PCT (Fig. 3 ). Thus, in the rat, most or all of ammonia secretion by the PCT occurs along its early portion.

The average length of the late PCT segment (measured between early and late proximal puncture sites) was $2.5 \mathrm{~mm}$ for experiments in which ammonia transport rates were measured. Because the total length of the surface PCT in Munich-Wistar rats averages $4.8 \mathrm{~mm}(14,15)$, the length of the early PCT segment (i.e., the length between glomerulus and early proximal puncture site) was, on average, $2.3 \mathrm{~mm}$. Thus, the early and late PCT segments were similar in length, with each segment comprising approximately one-half of the accessible PCT. Furthermore, because the total length of the proximal tubule in rats is $\sim 10 \mathrm{~mm}(3,17)$, each segment constituted a significant fraction (20-25\%) of total proximal tubule length. We conclude, therefore, that net ammonia secretion along the late PCT was not limited because a relatively short length of tubule was studied or because the late PCT segment was short compared with the early proximal segment.

Role of ammonia production rate. An important factor that could contribute to a difference in total ammonia transport rate in early vs. late proximal segments is a difference in the rate of ammonia production. Several observations support the view that ammonia production by the early PCT would exceed that in the late PCT in vivo. First, studies with intact tubule segments from normal rats have shown that the $S-1$ segment of the proximal tubule produces ammonium from glutamine at a much higher rate than the S- 2 segment when the segments are incubated under identical conditions in vitro (3). This finding indicates that cells of the early PCT (S-1) have a higher intrinsic capacity for am- 
monium production than cells of the late PCT (S-2), ${ }^{3}$ an observation consistent with the higher activity in S-1 of the primary ammonium-producing enzyme, phosphate-dependent glutaminase (18). A second variable that would contribute to higher ammonia production in the early PCT is a higher concentration of glutamine in the tubule lumen. In vitro microperfusion studies have shown that adding glutamine to the luminal perfusate greatly increases total ammonia production and secretion in proximal convoluted and proximal straight tubules (19). Absorption of glutamine in vivo is so rapid, however, that virtually all of filtered glutamine is reabsorbed within the first 1-2 mm of the PCT (20). As a result, the luminal glutamine concentration in fluid delivered to the late PCT is extremely low (0.06 vs. 0.6 $\mathrm{mM}$ in glomerular filtrate) (20). Thus, high luminal glutamine concentrations would stimulate ammonia production and secretion along the early PCT, whereas a near absence of luminal glutamine could limit production along the late PCT. Finally, a third variable that could affect ammonia production is luminal flow rate. Flow rate in the late PCT is considerably less than that in the early PCT in vivo (Table II). Decreases in luminal flow rate have been shown to reduce total ammonia production by proximal tubule segments, even in the absence of luminal glutamine (19).

All three of the variables outlined above could contribute to a reduced rate of ammonia production in the late PCT of control rats. In tubules from rats with chronic metabolic acidosis, the ammonia production rate measured in vitro is similar in $\mathrm{S}-1$ and S-2 segments (3); however, low luminal glutamine levels and a low luminal flow rate may still act to limit ammonia production in the late PCT during acidosis. Because the rate of cellular production is an important determinant of the rate of proximal tubule ammonia secretion $(3,6,7,16,19,21,34)$, it is likely that relatively high rates of ammonia production contribute to high rates of ammonia secretion in the early PCT, whereas lower rates of production may explain, in part, the finding that ammonia secretion is low or absent along the late PCT.

Role of luminal ammonia concentration. Another important factor that may limit ammonia secretion along the late PCT is the presence of high concentrations of ammonia in the tubule lumen. The ammonia concentration in fluid delivered to the early PCT (i.e., in the glomerular filtrate) is relatively low and is presumably similar to that in arterial plasma $(\sim 0.1 \mathrm{mM})$. The low luminal ammonia concentration would facilitate early proximal ammonia secretion because the secretion initially proceeds against little or no transepithelial ammonia concentration gradient. In contrast, luminal ammonia concentrations in fluid delivered to the late PCT are higher $(0.4-0.8 \mathrm{mM}$, Table II) because high rates of ammonia secretion along the early proximal segment rapidly raise luminal $\mathrm{NH}_{4}^{+}$and $\mathrm{NH}_{3}$ concentrations to values well above concentrations in arterial blood (Tables I and II, Fig. 4). As a result, ammonia secretion by the late proximal segment must proceed against substantial transepithelial $\mathrm{NH}_{4}^{+}$ and $\mathrm{NH}_{3}$ concentration gradients that are not present at the beginning of the early proximal segment. If a unidirectional flux of ammonia $\left(\mathrm{NH}_{4}^{+}\right.$and/or $\left.\mathrm{NH}_{3}\right)$ from lumen to cell, or from

3. In the rat, the $\mathrm{S}-1$ segment comprises the initial portion of the PCT; the S-2 segment includes the end of the PCT and the beginning of the proximal straight tubule (35). Although the exact point of transition is not known, the S-1 segment extends at least $1 \mathrm{~mm}$ beyond the glomerulus (35). In our experiments, it is likely that the early PCT consists primarily of S-1, whereas the late PCT consists of S-2. lumen to intercellular space, normally moderates the rate of net total ammonia secretion, then the higher average luminal ammonia concentration along the late PCT would be expected to reduce net ammonia secretion by promoting an increase in ammonia backflux. In contrast, in the early PCT, low concentrations of ammonia in the glomerular filtrate would tend to limit ammonia backflux and promote net ammonia secretion. Differences in total ammonia transport rate between the early and late PCT may be due, therefore, to differences in the rate of ammonia backflux that detracts from net secretion. In the late PCT of control rats, the rate of cellular ammonia production and secretion apparently is not sufficient to overcome the net ammonia efflux from lumen to blood and net total ammonia absorption is observed (Fig. 3). During chronic metabolic acidosis, ammonia production by the late PCT (S-2) is greatly increased (3) and the ammonia secretory flux is sufficient to overcome the net ammonia backflux. As a result, total ammonia concentration rises along the late PCT and small net secretion is observed (Figs. 1 and 3 ).

Although complete information on pathways of ammonia transport in the PCT is not yet available, it is reasonable to assume that passive diffusion of $\mathrm{NH}_{4}^{+}$would contribute to the net efflux of total ammonia from lumen to blood. A substantial $\mathrm{NH}_{4}^{+}$backflux was demonstrated recently in isolated proximal straight tubules from rabbits (22). To determine whether a backflux of $\mathrm{NH}_{4}^{+}$could materially affect net total ammonia transport in our experiments, rates of $\mathrm{NH}_{4}^{+}$diffusion from lumen to blood were estimated for the late PCT. Using an $\mathrm{NH}_{4}^{+}$permeability of $4.5 \times 10^{-5} \mathrm{~cm} / \mathrm{s}(22)$, a tubule diameter of $20 \mu \mathrm{m}$ and total ammonia concentrations in lumen and blood measured in the present study (Tables I and II), the calculated net diffusive flux of $\mathrm{NH}_{4}^{+}$from lumen to blood in late PCT would be $0.6 \mathrm{pmol} /$ $\mathrm{min}$ per $\mathrm{mm}$ for control rats and $1.8 \mathrm{pmol} / \mathrm{min}$ per $\mathrm{mm}$ in acidotic rats. ${ }^{4}$ For the total length of late PCT studied $(2.5 \mathrm{~mm})$, the net efflux of $\mathrm{NH}_{4}^{+}$would be $1.5 \mathrm{pmol} / \mathrm{min}$ in controls and $4.5 \mathrm{pmol} / \mathrm{min}$ in acidosis. Because these rates are similar to or greater than the net total ammonia transport rates measured in the late PCT (Fig. 3), it appears that $\mathrm{NH}_{4}^{+}$backflux would be an important determinant of net total ammonia transport rate and that such a backflux could limit or prevent net ammonia secretion along the late PCT in vivo.

Proximal tubule $\mathrm{NH}_{3}$ concentrations. Differences in total ammonia transport rate also were associated with differences in luminal $\mathrm{NH}_{3}$ concentration. In both control and acidotic rats, $\mathrm{NH}_{3}$ concentration in the early PCT was approximately twice that determined in the late PCT (Table III, Fig. 4). Because the early and late $\mathrm{PCT}$ values differ, the $\mathrm{NH}_{3}$ concentration in at least one of the segments presumably differs from the $\mathrm{NH}_{3}$ concentration in renal cortical blood. We believe it is likely that the $\mathrm{NH}_{3}$ concentration in the early PCT is above that in cortical blood. Luminal $\mathrm{NH}_{3}$ concentration in the early PCT in acidosis

4. The net diffusive flux of $\mathrm{NH}_{4}^{+}$from lumen to blood $\left(\mathrm{NH}_{4}^{+}, \mathrm{pmol} / \mathrm{min}\right.$ per mm) was calculated as $J_{\mathrm{NH}_{4}^{+}}^{+}=\dot{A} P_{\mathrm{NH}_{4}^{+}}^{+} \Delta C_{\mathrm{NH}_{4}^{+}}$, where $P_{\mathrm{NH}_{4}^{+}}$is permeability to $\mathrm{NH}_{4}^{+}$(in centimeters per second), $\Delta \mathrm{C}_{\mathrm{NH}_{4}^{+}}$is the arithmetic mean transepithelial $\mathrm{NH}_{4}^{+}$concentration difference (in millimoles per liter), and $A$ is surface area of the epithelium, assumed to be $6.1 \times 10^{-4}$ $\mathrm{cm}^{2} / \mathrm{mm}$ (20 $\mu \mathrm{m}$ diameter). The calculated rates may underestimate $\mathrm{NH}_{4}^{+}$backflux because transepithelial voltage, which is oriented lumen positive in the late PCT (36) and constitutes a driving force for $\mathrm{NH}_{4}^{+}$ efflux, was neglected in the calculations. On the other hand, the calculated rates may overestimate $\mathrm{NH}_{4}^{+}$efflux if the $\mathrm{NH}_{4}^{+}$concentration of renal cortical blood significantly exceeds that of systemic arterial blood. 
was $9.6 \mu \mathrm{M}$, a value six times greater than the $\mathrm{NH}_{3}$ concentration determined in arterial plasma $(1.6 \mu \mathrm{M})$. If the $\mathrm{NH}_{3}$ concentration in cortical blood was identical to that in the early PCT, the total ammonia concentration in cortical blood in acidosis would exceed $0.6 \mathrm{mM}$ (assuming blood $\mathrm{pH}=7.22$, Table I). This value is considerably higher than total ammonia concentrations in rat renal venous blood $(23,24)$. It is possible that cellular ammonia production coupled with vascular-vascular exchange could elevate renal cortical $\mathrm{NH}_{3}$ concentrations to values above renal venous values, as is observed for $\mathrm{CO}_{2}(25,26)$. However, this effect would be unlikely to elevate cortical $\mathrm{NH}_{3}$ concentration above systemic blood by $>60-70 \%$ (26), whereas an increase of as much as $500 \%$ would be required for renal blood to be equilibrated with the $\mathrm{NH}_{3}$ concentration in the early PCT (Fig. 4). Whether $\mathrm{NH}_{3}$ concentrations in the late PCT differ from concentrations in stellate vessel and peritubular capillary blood remains to be determined.

The conclusion that luminal $\mathrm{NH}_{3}$ concentration in the early PCT exceeds that in renal cortical blood also is consistent with recent studies on isolated mouse proximal tubules. Nagami and Kurokawa (19) measured ammonia production and secretion by proximal tubule segments that were perfused and bathed in vitro with solutions that were initially ammonia free. Although ammonia produced by the tubule cells was secreted into both the luminal and bathing solutions, the total ammonia concentration in fluid exiting the tubule lumen was 300 times that measured in the bath. Because the proximal tubule can lower lumen $\mathrm{pH}$ by, at most, $1.0 \mathrm{U}(27)$, the lumen-to-bath $\mathrm{NH}_{4}^{+}$concentration ratio could not exceed 10 if the $\mathrm{NH}_{3}$ concentration in bath and lumen were identical. Because luminal $\mathrm{NH}_{4}^{+}$concentration exceeded that in the bath by 300 -fold, the luminal $\mathrm{NH}_{3}$ concentration also greatly exceeded that in the bath. This observation, coupled with our finding that luminal $\mathrm{NH}_{3}$ concentration in the early PCT exceeds that expected for renal cortical blood, indicates that the proximal tubule is able to generate and maintain a concentration gradient for $\mathrm{NH}_{3}$ across its tubule wall. These results are consistent with the presence of a specialized process that mediates preferential addition of synthesized ammonia to the proximal tubule lumen. Some of the possible mechanisms that may be involved in this transfer process have been discussed previously $(16,19)$.

The presence of high luminal $\mathrm{NH}_{3}$ concentrations in the early PCT also could provide an additional explanation for the limited rate of ammonia secretion observed along the late PCT. If the luminal $\mathrm{NH}_{3}$ concentration generated in the early PCT was similar to the $\mathrm{NH}_{3}$ concentration in cells of the late PCT, net diffusion of $\mathrm{NH}_{3}$ from cell to lumen would be impaired. If the luminal $\mathrm{NH}_{3}$ concentration were to exceed intracellular $\mathrm{NH}_{3}$ concentration, then net diffusion of $\mathrm{NH}_{3}$ from lumen to cell, or from lumen to blood, could result. Such a process could contribute to net absorption of ammonia along the late PCT in control rats. ${ }^{5}$ The finding that luminal $\mathrm{NH}_{3}$ concentration falls along the late PCT (Fig. 4) indicates that the transepithelial $\mathrm{NH}_{3}$

5. The estimated net diffusive flux of $\mathrm{NH}_{3}$ from lumen to blood for the late PCT would be $2.1 \mathrm{pmol} / \mathrm{min}$ per $\mathrm{mm}$ in control rats and $3.3 \mathrm{pmol} /$ min per mm in acidosis $\left(J_{\mathrm{NH}_{3}}=A P_{\mathrm{NH}_{3}} \Delta C_{\mathrm{NH}_{3}}\right.$, where $P_{\mathrm{NH}_{3}}=1.5 \times 10^{-2}$ $\mathrm{cm} / \mathrm{s}(22), \Delta C$ is arithmetic mean transepithelial concentration gradient, and $A$ is epithelial surface area (20 $\mu \mathrm{m}$ diameter). These rates are comparable to net total ammonia transport rates (Fig. 3), indicating that $\mathrm{NH}_{3}$ backflux could limit or prevent net ammonia secretion by the late PCT in vivo. concentration gradients generated in the early proximal segment are not maintained along the late proximal segment. Two possible explanations for this finding are a difference in $\mathrm{NH}_{3}$ permeability or a difference in intracellular $\mathrm{NH}_{3}$ concentration in early and late proximal segments. Whether cellular $\mathrm{NH}_{3}$ concentrations differ in the early and late PCT has not been determined. It is conceivable, however, that intracellular $\mathrm{NH}_{3}$ concentration in the early PCT could exceed that in the late PCT because of a higher intrinsic rate of ammonia production or because of a higher intracellular $\mathrm{pH}$, the latter due to the higher acid secretion rate known to exist in the early proximal segment (14).

Relation to previous studies. The observation that luminal $\mathrm{NH}_{3}$ concentration differs in the early and late PCT is in contrast to the generally accepted view that $\mathrm{NH}_{3}$ is in diffusion equilibrium throughout the renal cortex $(1,28)$. This view was supported originally by indirect studies using whole kidney clearance techniques (28-30); however, it is unlikely that these studies would have detected small differences in $\mathrm{NH}_{3}$ concentration among individual tubule segments. In a more direct study using micropuncture techniques, Oelert et al. found no difference in $\mathrm{NH}_{3}$ concentration between different segments of the PCT or between proximal and distal tubule (31). In that study, PCTs were punctured randomly and $\mathrm{NH}_{3}$ concentrations were not compared in different segments of the same tubule. This limitation, coupled with a significant degree of variability in calculated $\mathrm{PNH}_{3}$ values (31), may have caused small differences in $\mathrm{NH}_{3}$ concentration to go undetected. Our results show that $\mathrm{NH}_{3}$ concentration in the early PCT exceeds that in the late PCT when values are compared in different segments of the same tubule. Recent studies have also demonstrated a difference in $\mathrm{NH}_{3}$ concentration between the late PCT and early distal tubule in control and acidotic rats (32).

Although ammonia transport rates had not been measured previously in different portions of the proximal tubule in vivo, results consistent with net absorption of ammonia along the late PCT have been reported. In rats in normal acid-base balance, Karlmark and Danielson observed no apparent increase in luminal ammonia concentration along the late PCT despite an increase in the TF/P inulin ratio from 1.5 to 3.0 (33). They inferred that ammonia or ammonium was absorbed along the proximal tubule in parallel with water. These findings could be questioned because early PCT ammonia concentrations may be falsely elevated when measured by the formaldehyde-titration technique (33). However, Hayes et al. (5), using a different assay technique, also observed no apparent increase in total ammonia concentration along the late portion of the surface PCT of the rat in vivo. Our results demonstrate directly that luminal total ammonia concentration remains constant, and that net absorption of total ammonia occurs, along the late PCT of control rats in vivo.

Although our results demonstrate that net ammonia secretion was absent or occurred at a low rate along the late PCT, this should not be taken as evidence that the PCT did not contribute importantly to renal ammonium excretion. Ammonium delivery to the end of the PCT could account for $\sim 50 \%$ of excreted ammonium in acidotic rats and $65 \%$ of ammonium excretion in control rats. These findings are in agreement with previous studies demonstrating that a large fraction of excreted ammonium is present at the end of the surface PCT of the rat in vivo $(4-7,21,32)$. Our results demonstrate, however, that most or all of the ammonium delivered to the end of the PCT is actually 
secreted along the initial few millimeters of that segment. Our results also show that during chronic metabolic acidosis an important fraction ( 50\%) of excreted ammonium is secreted by nephron segments beyond the PCT. Because production and secretion of ammonium by the initial portion of the proximal straight tubule (S-2) increase dramatically in response to chronic metabolic acidosis $(3,34)$, it is likely that this segment can account for a large portion of ammonium production and secretion that occurs beyond the PCT. As demonstrated recently, transport processes involved in countercurrent trapping of ammonia in the renal medulla also play an important role in promoting ammonium excretion during chronic metabolic acidosis (12).

In summary, these studies demonstrate that total ammonia transport rate varies along the length of the PCT of the rat in vivo. In control rats, net ammonia secretion occurs along the early PCT but net ammonia absorption occurs along the late PCT. In rats with chronic metabolic acidosis, ammonia is secreted along both the early and late PCT; however, the rate of ammonia secretion in the early PCT is six times greater than that in the late PCT. Thus, most or all of ammonia secretion by the PCT occurs along its early portion. Luminal $\mathrm{NH}_{3}$ concentration in the early PCT is significantly greater than that in the late PCT, which indicates that $\mathrm{NH}_{3}$ is not in diffusion equilibrium throughout the renal cortex. It is proposed that differences in ammonia transport rate in early vs. late PCT are due to differences in ammonia production rate and/or to differences in luminal ammonia concentration. In the early PCT, high rates of ammonia production would promote net ammonia secretion and low ammonia concentrations in the glomerular filtrate would tend to limit ammonia backflux from lumen to blood. In contrast, in the late PCT, a lower ammonia production rate may limit the ammonia secretory flux and relatively high luminal $\mathrm{NH}_{4}^{+}$and $\mathrm{NH}_{3}$ concentrations delivered to that segment would promote an increase in ammonia backflux that detracts from net ammonia secretion.

\section{Acknowledgments}

We thank Carlton Caflisch, Ph.D., for constructing the pH microelectrodes and aiding in the pH measurements. We also thank Galen Bevel for technical assistance and Gail Pollard for secretarial assistance.

These experiments were supported, in part, by National Institutes of Health grant R01 AM30603. Dr. DuBose was the recipient of a National Institutes of Health Research Career Development Award (K04 AM 01033) during a portion of this study.

\section{References}

1. Halperin, M. L., M. S. Goldstein, B. J. Steinbaugh, and R. L. Jungas. 1985. Biochemistry and physiology of ammonium excretion. In The Kidney: Physiology and Pathophysiology. D. W. Seldin and G. Giebisch, editors. Raven Press, New York. 1471-1490.

2. Walser, M. Roles of urea production, ammonium excretion, and amino acid oxidation in acid-base balance. 1986. Am. J. Physiol. 250: F181-F188.

3. Good, D. W., and M. B. Burg. 1984. Ammonia production by individual segments of the rat nephron. $J$. Clin. Invest. 73:602-610.

4. Glabman, S., R. M. Klose, and G. Giebisch. 1963. Micropuncture study of ammonia excretion in the rat. Am. J. Physiol. 205:127-132.

5. Hayes, C. P., Jr., J. S. Mayson, E. E. Owen, and R. Robinson. 1964. A micropuncture evaluation of renal ammonia excretion in the rat. Am. J. Physiol. 207:77-83.

6. Sajo, I. M., M. B. Goldstein, H. Sonnenberg, B. J. Stinebaugh, D. R. Wilson, and M. L. Halperin. 1981. Sites of ammonia addition to tubular fluid in rats with chronic metabolic acidosis. Kidney Int. 20:353358 ,

7. Buerkert, J., D. Martin, and D. Trigg. 1982. Ammonium handling by superficial and juxtamedullary nephrons in the rat. Evidence for an ammonia shunt between the loop of Henle and the collecting duct. $J$. Clin. Invest. 70:1-12.

8. DuBose, T. D., Jr, D. W. Seldin, and J. P. Kokko. 1978. Segmental chloride reabsorption in the rat nephron as a function of load. Am. J. Physiol. 3:F97-F105.

9. Higashihara, E., J. B. Stokes, J. P. Kokko, W. B. Campbell, and T. D. DuBose, Jr. 1979. Cortical and papillary micropuncture examination of chloride transport in segments of the rat kidney during inhibition of prostaglandin production. Possible role for prostaglandins in the chloruresis of acute volume expansion. J. Clin. Invest. 64:1277-1287.

10. DuBose, T. D., Jr., L. R. Pucacco, D. W. Seldin, N. W. Carter and J. P. Kokko. 1978. Direct determination of $\mathrm{PCO}_{2}$ in the rat renal cortex. J. Clin. Invest. 62:338-348.

11. Good, D. W. and G. G. Vurek. 1983. Picomole quantitation of ammonia by flow-through fluorometry. Anal. Biochem. 130:199-202.

12. Good, D. W., C. R. Caflisch, and T. D. DuBose, Jr. 1987. Transepithelial ammonia concentration gradients in inner medulla of the rat. Am. J. Physiol. In press.

13. DuBose, T. D., Jr., L. R. Pucacco and N. W. Carter. 1981. Determination of disequilibrium $\mathrm{pH}$ in the rat kidney in vivo: evidence for hydrogen secretion. Am. J. Physiol. 240:F138-F146.

14. Liu, F. Y. and M. G. Cogan. 1984. Axial heterogeneity in the rat proximal convoluted tubule. I. Bicarbonate, chloride, and water transport. Am. J. Physiol. 247:F816-F821.

15. Corman, B., R. Thomas, R. McLeod, and C. deRouffignac. 1980. Water and total $\mathrm{CO}_{2}$ reabsorption along the rat proximal convoluted tubule. Pflugers Arch. Eur. J. Physiol. 389:45-53.

16. Good, D. W., and M. A. Knepper. 1985. Ammonia transport in the mammalian kidney. Am. J. Physiol. 248:F459-F471.

17. Sperber, I. Studies on the mammalian kidney. 1944. Zool. Bidr. Uppsala. 22:249-431.

18. Curthoys, N. P. and O. H. Lowry. 1973. The distribution of glutaminase isoenzymes in the various structures of the nephron in normal, acidotic, and alkalotic rat kidney. J. Biol. Chem. 248:162-168.

19. Nagami, G. T. and K. Kurokawa. 1985. Regulation of ammonia production by mouse proximal tubules perfused in vitro. Effect of luminal perfusion. J. Clin. Invest. 75:844-849.

20. Silbernagl, S. 1980. Tubular reabsorption of 1-glutamine studied by free-flow micropuncture and microperfusion of rat kidney. Int. J. Biochem. 12:9-16.

21. Simon, E., D. Martin, and J. Buerkert. 1983. Handling of ammonia by the renal proximal tubule during acute metabolic acidosis. Am. J. Physiol. 245:F680-F686.

22. Garvin, J. L., M. B. Burg, and M. A. Knepper. 1987. $\mathrm{NH}_{3}$ and $\mathrm{NH}_{4}^{+}$transport by rabbit renal proximal straight tubules. Am. J. Physiol. In press.

23. Vinay, P., E. Allignet, C. Pichette, M. Watford, G. Lemieux, and A. Gougoux. 1980. Changes in renal metabolite profile and ammoniagenesis during acute and chronic metabolic acidosis in dog and rat. Kidney Int. 17:312-325.

24. Stern, L., K. A. Backman and J. P. Hayslett. 1985. Effect of cortical-medullary gradient for ammonia on urinary excretion of ammonia. Kidney Int. 27:652-661.

25. DuBose, T. D., Jr., C. R. Caflisch, and A. Bidani. 1984. Role of metabolic $\mathrm{CO}_{2}$ production in the generation of elevated renal cortical $\mathrm{PCO}_{2}$. Am. J. Physiol. 246:F592-F599.

26. Bidani, A., E. D. Crandall, and T. D. DuBose, Jr. 1984. Analysis of the determinants of renal cortical $\mathrm{PCO}_{2}$. Am. J. Physiol. 247 (Suppl. 16):F466-F474.

27. Koeppen, B., G. Giebisch, and G. Malnic. 1985. Mechanism and regulation of renal tubular acidification. In The Kidney: Physiology and Pathophysiology. D. W. Seldin and G. Giebisch, editors. Raven Press, New York. 1491-1525. 
28. Pitts, R. F. 1973. Production and excretion of ammonia in relation to acid-base regulation. In Handbook of Physiology. Section 8, Renal Physiology. J. Orloff and R. W. Berliner, editors. American Physiological Society, Washington, D. C. Waverly Press, Baltimore, MD. 455-496.

29. Denis, G., H. Preuss, and R. Pitts. 1964. The $\mathrm{PNH}_{3}$ of renal tubular cells. J. Clin. Invest. 43:571-582.

30. Stone, W. J., S. Balagura, and R. F. Pitts. 1967. Diffusion equilibrium for ammonia in the kidney of the acidotic dog. J. Clin. Invest. 46:1603-1608.

31. Oelert, H., E. Uhlich, and A. G. Hills. 1968. Messungen des ammoniakdruckes in den corticalen tubuli der rattenniere. Pfluegers Arch. Eur. J. Physiol. 300:35-48.

32. Simon, E., D. Martin, and J. Buerkert. Contribution of individual superficial nephron segments to ammonium handling in chronic met- abolic acidosis in the rat. Evidence for ammonia disequilibrium in the renal cortex. J. Clin. Invest. 76:855-864.

33. Karlmark, B., and B. G. Danielson. 1974. Titratable acid, $\mathrm{PCO}_{2}$, bicarbonate and ammonium ions along the rat proximal tubule. Acta Physiol. Scand. 91:243-258.

34. Nagami, G. T., C. M. Sonu, and K. Kurokawa. 1986. Ammonia production by isolated mouse proximal convoluted tubules perfused in vitro. Effect of metabolic acidosis. J. Clin. Invest. 78:124-129.

35. Maunsbach, A. B. 1966. Observations on the segmentation of the proximal tubule in the rat kidney. Comparison of results from phase contrast, fluorescence and electron microscopy. J. Ultrastruct. Res. 16: 239-258.

36. Burg, M., and D. W. Good. 1983. Sodium chloride coupled transport in mammalian nephrons. Ann. Rev. Physiol. 45:533-547. 